\title{
Psychoform and somatoform dissociation among children and adolescents: An evaluation of a new short screening instrument for dissociation, DSQ-
}

\section{2}

Doris Nilsson, Sara Green, Carl Göran Svedin and Örjan Dahlström

The self-archived postprint version of this journal article is available at Linköping University Institutional Repository (DiVA):

http://urn.kb.se/resolve?urn=urn:nbn:se:liu:diva-160532

N.B.: When citing this work, cite the original publication.

Nilsson, D., Green, S., Svedin, C. G., Dahlström, Ö., (2019), Psychoform and somatoform dissociation among children and adolescents: An evaluation of a new short screening instrument for dissociation, DSQ-12, European journal of trauma and dissociation, , 1-8.

https://doi.org/10.1016/j.ejtd.2019.07.001

Original publication available at:

https://doi.org/10.1016/j.ejtd.2019.07.001

Copyright: Elsevier

http://www.elsevier.com/

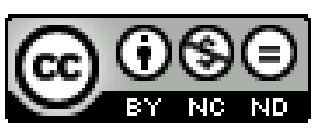


Psychoform and somatoform dissociation among children and adolescents: An evaluation of a new short screening instrument for dissociation, DSQ-12. 


\begin{abstract}
Introduction: Today's assessment instruments for dissociation among adolescents are either relatively extensive or are specifically designed to identify either psychoform or somatoform dissociation. Objective: A questionnaire that is shorter than any of the existing questionnaires and is concerned with both forms of dissociation would be helpful for both clinicians and researchers. Method: Existing data from 462 adolescents who had answered Dis-Q Sweden and SDQ-20 were used to create a new questionnaire consisting of 12 items. A pilot study with 42 participants 15-19 years old, was carried out to test this new instrument, Dissociation Screening Questionnaire 12 (DSQ-12). DSQ-12 was then tested on 451 adolescents 10 to 20 years old. A matched clinical group of 25 adolescents in the same age range was used, in order to test the classification performance of DSQ-12. Results showed good reliability, convergent and construct validity was satisfactory, and dissociation differed between age groups as well as between genders. Conclusions are that the developed DSQ-12 performed well psychometrically, was reliable and valid. DSQ-12 is easy to answer and is suitable for clinical screening purposes and future research.
\end{abstract}

Keywords: DSQ-12; psycho and somatoform dissociation; children and adolescents; psychometrics 


\section{Introduction}

Today's screening instruments for dissociation in children and adolescents are either relatively extensive or are specifically designed to identify either psychoform or somatoform dissociation. From a clinical point of view these two forms of dissociation often exist together (Jepsen, et al., 2014; Pullin, et al., 2014; Soukup, et al., 2010). The possibility to screen for both using a comprehensive instrument is valuable for both clinical and research use (Sar \& Ross, 2006). There is today a lack of research concerning dissociation among children and adolescents both in normative and clinical populations and our knowledge about similarities or differences in levels of dissociation concerning gender and age is sparse.

There are multiple varieties of dissociative disorders, which affect the normal integration of consciousness, memory, identity, emotion, perception, body representation, motor control and behavior in the form of disruption and/or discontinuity (Sar, 2014). The symptoms can be fragmentation of identity, depersonalization, derealization, numbing or amnesia (DSM-5, 2013). The dissociative spectrum ranges from normal and every day blocking to severe psychological problems (Putnam, 1997). Dissociative symptoms can coexist with other psychological conditions (Comasco et al., 2015; Kozlowska et al., 2007; Sar et al., 2009; Sar, 2014).

An ulterior affective, cognitive or neuropsychiatric disorder can cause a child to be extra sensitive in a potentially traumatic environment and thereby develop a dissociative comorbidity (Bob et al., 2013; Comasco et. al, 2015). Studies have found, for example, that persons with eating disorders often also have dissociative symptoms and a background of traumatic experiences (Gerke et al., 2006; McShane \& Zirkel, 2008, Vanderlinden \& Vandereycken, 
1997). Studies concerning children and adolescents are few and rather old, and we do not know very much about dissociative symptoms among young people or how common they are.

Since well-designed treatment given to a child experiencing dissociation sometimes lead to quick recovery (Putnam, 1997; Silberg \&Waters, 1996) it is important to support clinicians by providing easily administered and valid screening instruments

\section{Psychoform and somatoform dissociation}

Psychoform dissociation encompasses the symptom clusters dissociative amnesia, depersonalisation, derealisation, identity confusion/identity fragmentation, and identity alteration (Steinberg, 1994). Psychoform dissociation refers to the separation or malintegration of mental content that under normal circumstances would be integrated or processed together (Steinberg, 1994). Somatoform dissociation refers to physical symptoms signifying a general medical condition that appears upon reactivation of dissociative states (Nijenhuis, 2004). Somatoform dissociation is manifested as a loss of the normal integration of bodily components such as disturbances of sensation, movement, and other bodily functions. As mentioned above, the two conditions psychoform and somatoform dissociation clinically have been found to appear together (Jepsen et al., 2014; Pullin et al., 2014; Soukup et al., 2010); in several studies a strong correlation has been observed between the two conditions (Nijenhuis et al. 1996; Farina et al., 2011; Nilsson et al., 2014). It has also been found that high levels of both psychoform and somatoform dissociative symptoms have strong co-morbidity with depressive symptoms and suicidal tendencies (Maaranen et al., 2004)

Nevertheless, in the Diagnostic and Statistical Manual of Mental disorders (DSM-5, 2013), psychoform dissociation has been placed in one category and somatoform dissociation in 
another under somatic disorders. However, in the International Classification of Diseases (ICD10 and ICD-11) the various expressions of conversion disorder, such as medically unexplained motor weakness, loss of other sensory functions such as touch, sight, and hearing, and nonepileptic seizures are categorised under the heading dissociative disorders.

\begin{abstract}
Aim
The aim of this study was to develop a new short screening questionnaire regarding dissociation for children and adolescents that would be easy to complete. This new instrument would be able to identify the two important aspects of dissociation; psychoform and somatoform dissociation. A second goal was to investigate the psychometrics of the new instrument. A third goal was to collect data concerning dissociative symptoms from a group of non-clinical adolescents and a hypothesis was that girls would show more dissociative symptoms than boys.
\end{abstract}

\title{
Materials and Method
}

To accomplish these aims, the study was carried out in three steps; first; creating the new scale, second, testing the screening instrument in a minor pilot study, and third; collecting data from a larger child and adolescent sample.

\section{Instruments}

There are two well-known self-rating questionnaires; the Dissociation Questionnaire (Dis-Q, Vanderlinden, 1993) and the Somatoform Dissociation Questionnaire (SDQ-20, Nienijhuis et al., 1996) measuring dissociation. The Dis-Q is designed to identify mainly the psychoform type and the SDQ-20 is focused on somatic symptoms (Mueller-Pfeiffer et al., 2010). These two questionnaires have been shown to have good psychometrics regarding dissociation.

The Dissociation questionnaire (Dis-Q) was originally developed by Vanderlinden and colleagues (1993) as an instrument for assessing dissociative symptoms. The Dis-Q has 63 
items, which are to be answered on a Likert scale 1-5. The Dis-Q has been translated into Swedish and used in several studies in Sweden and called Dis-Q-Sweden (Nilsson \& Svedin, 2006a; Nilsson \& Svedin, 2006b). Dis-Q-Sweden has been found to be useful in identifying possible dissociative symptoms.

The Somatoform Dissociation Questionnaire-20 (SDQ-20) was developed by Nijenhuis et al., (1996). The scale was proven to be satisfactory with good internal consistency $(\alpha=0.95)$ as well as validity with results showing a significant correlation with results from Dis-Q. Nijenhuis and colleagues (1996) also created a short version SDQ-5 and suggested it might be used as a screening instrument. The SDQ-20 has been translated and used in several countries (Kukla et al., 2010; Mueller-Pfeiffer et al., 2010; Pullin et al., 2012). It contains 20 questions which are to be answered on a Likert-scale from 1-5 (Mueller-Pfeiffer et al., 2010). The SDQ20 and SDQ-5 have also been translated into Swedish and tested (Nilsson et al., 2014) concerning their validity and reliability. Testing of the short version SDQ-5 showed that the reliability was lower than expected. In the study both a clinical and a nonclinical group were used where $\alpha$ was 0.50 and 0.64 for SDQ-5. However, the results from the test showed high internal consistency with $\alpha 0.83$ and 0.84 for SDQ-20.

The Trauma Symptom Checklist for Children (TSCC) was developed by Briere (Briere, 1996) and aims to identify traumatic symptomatology in children and adolescents. The scale consists of 54 items and includes six sub-scales; Anxiety, Depression, Anger, Posttraumatic Stress, Sexual Concerns and Dissociation (Briere, 1996). The subscale Dissociation was chosen for the purpose of this study. It is a four-point Likert scale ranging from 0 ("never") to 3 ("almost all of the time") (Lanktree et al., 2008). TSCC has been translated and validated with good psychometric properties within a Swedish condition. In both a normative and a clinical setting, the TSCC scale obtained an internal consistency of .94 for the total scale and (Nilsson, Wadsby $\&$ Svedin, 2008) and for the subscale dissociation $\alpha=.83$ (Nilsson $\&$ Svedin, 2010). Also test- 
retest has been reported and found to be for the total scale $r=.81$ and $r=.67$ for the subscale dissociation (Nilsson, et al. 2008).

\section{Development process}

\section{Step 1: Developing the new questionnaire}

The first step in creating a new questionnaire was to use existing data $(n=462)$ on the Dis-QSweden and SDQ-20 to do an item-total correlation in order to find the most suitable questions. The data were acquired from a previous study with 462 participants age 15-20 (Nilsson et al., 2011). An item-total correlation was carried out for both Dis-Q-Sweden and SDQ-20 separately using SPSS version 21. We were able to discuss and get advices from clinicians on how to choose the most satisfactory questions.

\section{Second step: The pilot study}

A pilot study was then carried out with an additional questionnaire measuring dissociation (subscale Dissociation on TSCC) to compare results obtaining by using the newly developed questions with an already existing scale. The 10 dissociation subscale items in TSCC are: 5, 11, 18, 29, 30, 31, 38, 45, 48 and 53 (Nilsson, et al., 2008).

A convenience sample, which was considered suitable for pilot testing, was made where nearby high schools were contacted (Bryman, 2001). To attract schools to participate, a letter was sent out to principals with information about the project, a letter containing information about the collaboration between Linköping University and the Child and Adolescent Psychiatry unit (BUP-Elephant) a specialized unit for treating children and adolescents who have been sexually and/or physically abused. The schools were also given 100 Swedish crowns per completed questionnaire packet as compensation for their effort. 
The questionnaire packet had a cover page with demographic questions (age and gender) and information explaining that the survey was voluntary, anonymous, how it would be used, and that participants could stop whenever they wanted (Bryman, 2001). The information was presented both on the cover page and verbally by one of the researchers who was present in the classroom.

Finally, the pilot study was carried out at a high school where all students were 16 years of age or older and therefore did not need the consent of the parents (Codex, 2013). Then 50 questionnaires were distributed high school students from two schools and 42 questionnaire packets were returned. The data were encoded into SPSS and statistical analyses such as Cronbach's alpha and Pearson's correlation with the dissociation subscale on TSCC were carried out.

\section{Step 3: The main study}

After the pilot study was completed, 500 questionnaires were distributed to students ranging from 10 to 20 years old; in the end 451 completed questionnaires were received. The group consisted of adolescents $(\mathrm{N}=451)$ from schools in the middle of Sweden $(\mathrm{n}=171$ boys and $\mathrm{n}=271$ girls, age between $10-12$ years old, $\mathrm{n}=121,13-15$ years old $\mathrm{n}=120$, and $16-20$ years old, $\mathrm{n}=212$ ). The age range for these 451 was $10-20$ years of age, which meant that parental consent had to be given for some school classes/children (Codex, 2013). This was achieved by sending letters to the parents with all the information given to the schools and the children. At the end of the letter the parents signed, thus giving their consent. Children for whom consent was not given were not allowed to participate in the study. Even with consent from their parents, the children had a choice not to participate. None of the students declined to take part, the only reason for not participating was absence in class. 
Compensation for the schools/children was such that they could choose between getting 70 crowns or a cinema ticket per completed questionnaire packet.

To ensure that the study followed and maintained ethical standards with respect to the appropriate ethical regulations devised by the Swedish Research Council and Uppsala University, the CODEX rules and guidelines for research were followed (Codex, 2013).

To further test the DSQ-12 concerning the ability to classify individuals as clinical or nonclinical, we used data from another study with a clinical group with eating disorder who had responded to both Dis-Q-Sweden and SDQ-20. The items belonging to DSQ-12 were then selected and analyzed. The clinical group with eating disorder patients was chosen as it is not uncommon that this group show dissociative symptoms, both psychoform and somatoform (Beato, Rodriguez Cano, \& Belmonte, 2003; Nijenhuis, 2009). Sixty females aged 14 to 30 years had participated in a former study who met ICD-10 (WHO, 1992) criteria for eating disorder diagnoses. The group included patients with anorexia nervosa $(\mathrm{n}=20)$, atypical anorexia nervosa $(n=12)$, bulimia nervosa $(\mathrm{n}=5)$, atypical bulimia nervosa $(\mathrm{n}=4)$, overeating associated with other psychological disturbances $(n=1)$, other eating disorders $(\mathrm{n}$ $=1)$ and eating disorders, unspecified $(\mathrm{n}=17)$. The participants were recruited from a Child and Adolescent Psychiatric outpatient unit specializing in eating disorders and were diagnosed by experienced clinicians, physicians and therapists. From this eating disorder group 25 female adolescents were chosen for analyses together with 122 female adolescents from the normative group matched for age (16-20 years) and gender (females).

The clinical study was carried out in a Child and Adolescents psychiatric clinic and had been approved by the Human Research Ethics Committee, Faculty of Health Sciences, Linköping University (Dnr. 02-196). All participants had given informed consent. 


\section{Data analyses}

First, factors were examined. Data were randomly split into a training-set $(50 \%$ of the total study sample) and a test-set, both matched on gender and age-group. An Exploratory Factor Analysis (EFA) with the mean- and variance-adjusted weighted least squares (WLSMV) estimator and geomin rotation (allowing for correlations between factors) was performed on the training-set. Number of factors retained in the factor model were based on Kaiser's criterion and inspection of the scree plot. The factor model was thereafter tested using a Confirmatory Factor Analysis (CFA) on the test-set data along with a theoretically motivated factor model with two factors (the first factor containing the psychoform-items only and the second factor containing the somatoform-items only). Overall model fit was tested by Chi-square $\left(\chi^{2}\right)$ statistics and fit indices provided by the Mplus output: Root Mean Square Error of Approximation (RMSEA), Comparative Fit Index (CFI), Tucker-Lewis Index (TLI, also known as the Non-normed fit index [NNFI]) Standardized Root Mean Square Residual (SRMR; in the EFA only) and the Weighted Root Mean Square Residual (WRMR; in the CFA). Using guiding principles by Brown (2006), several different fit indices were used. For convenience of reporting, a model was judged as having good fit when the overall picture of fit indices indicated good fit and excellent if all of them indicated good fit: RMSEA $\leq .05$, CFI and TLI $\geq .95$, and SRMR $<.08$ or WRMR < .90 (see e.g., Hu \& Bentler, 1999; Yu, 2002).

Second, concurrent validity was examined by correlations between factor scores TSCC dissociation subscale (sum of TSCC-items 5, 11, 18, 29, 30, 31, 38, 45, 48 and 53) were examined using Spearman correlation.

Third, reliability of factors was examined using Cronbach's alpha (given the ordinal scales of the questions Cronbach's alpha will, if anything, underestimate the reliability). Variables included were those with significant loadings on respective factor. 
Fourth, normative values were produced by for each factor summarizing the scores of questions loading on that factor and by thereafter comparing scores between the age groups, and between girls and boys, Mann-Whitney U test and Kruskal-Wallis test (and Dunn's test as post-hoc test).

Reference values divided by gender and age-groups are given as $84^{\text {th }}$ percentiles for different factor scores $\left(84^{\text {th }}\right.$ percentile represents a T-score of 60 , i.e. the value corresponding to one standard-deviation above group mean in normal distributed samples).

Fifth, the performance of DSQ-12 was tested by evaluating the sensitivity and the specificity for different cut-off values using one composite score (sum of responses of each of the 12 questions) to classify individuals into a normal or a clinical group. The overall performance was measured by the area under the ROC curve (AUC).

Factor analyses were performed using Mplus version 7.4, correlations and Cronbach's alpha were examined using SPSS Version 23 and comparisons between groups were performed using R (v3.5.1) and RStudio (v1.1.456).

\section{Results}

\section{First step: the development of the new scale DSQ-12}

The eight Dis-Q items with the highest item-total correlations were chosen, these were items $3,11,12,17,20,28,41$ and 57 . The correlations of these eight items with the total score are shown in table 1, where the new item numbers used in the screening instrument DSQ-12 are presented. The top eight items were quite similar, concerning correlations, which made the clinicians' advice important as to not only choose the items with the highest value/loading and therefore get too alike questions. The item-total correlations were high. The items chosen from 
SDQ-20 were 7, 15, 19 and 20. These four items are also shown in table 1, showing their itemtotal correlation score and new item numbers to be used in the screening instrument DSQ-12. The clinicians argued that it was important to include items referring to attacks like epilepsy, number twelve on table in favor of item 3 on the SDQ-20 "I hear sounds close to me as if they came from far away" even if the loading was only marginal lower than the item chosen. The discussions with clinicians about the items, which to include or exclude were important in order to get the most functional items for the screening questionnaire.

Consequently, the new self-rating Dissociation Screening Questionnaire-12 (DSQ-12) contains 12 items chosen from the Dis-Q and the SDQ-20, data extraction from $n=462$ adolescent answers. The DSQ-12 uses a Likert-scale with answer options ranging from 1 (never) to 5 (always). See table 1 for the whole new scale.

\section{Insert table 1 here}

\section{The second step: the pilot study}

The pilot study contained answers from adolescents $(n=42)$, answering the new scale DSQ-12 and the dissociation subscale on the TSCC. The DSQ-12 and the subscale dissociation from the TSCC showed a high correlation ( $\mathrm{r}=.81)$. Cronbach's alpha was found to be $\alpha=.89$ for the DSQ-12.

\section{The third step: the main study}

The results cover the psychometrics of the new DSQ-12 from the $n=451$ participants in this main study and from a clinical group of eating disorder adolescents $n=25$ 


\section{Factors}

Results from EFA suggested a two-factor solution (eigenvalues of 7.55 and 1.08 with all remaining eigenvalues less than 0.88 ). The model showed logic on a theoretical level, the first factor (F1) was named psychoform factor and the second (F2) somatoform factor (Table 2). Four items loaded significantly on both factors. Items 1 and 2 comes from the DIS-Q but both relates to physical aspects in terms of feelings or actions related to the body. Item 11 comes from the SDQ-20 is actually very similar to item 1, but deals with feelings/thoughts about the body, and not physical sensations per se. item 4 comes from the DIS-Q (feeling confused) also loaded on both factors. The strongest loadings on the psychoform factor (based on CFA1) were items related to personality (item 8: mind split up; item 3: wonder who I am; item 4: feel confused; item 5: split personality; item 7: do something against my liking). For the somatoform factor, the strongest loadings (based on CFA1) were items related to not being able to act (item 10: paralyzed; item 11: grow stiff). In CFA1, item 4 did not load significantly on the somatoform factor, as compared to EFA. The theoretically defined model tested by CFA2 showed similar but slightly smaller model fit than the model tested by CFA1. Factors generated showed strong correlations with each other. (Figure 1).

Insert figure 1 about here

\section{Insert table 2 here}

\section{Concurrent validity}

The correlation between factor scores and the TSCC dissociation subscale varied between .61 and .76 (Table 2). 


\section{Reliability}

Cronbach's alpha for the different factors varied between .85 and .93 . (Table 2).

Normative values by gender and age

The DSQ-12 contains 12 items which are rated on a scale from 1-5. In the factor model based on the EFA, the psychform factor (factor 1) consists of 9 items and its composite scores can therefore range from 9 to 45 . The somatoform factor (factor 2) consists of 7 items and its composite scores can therefore range from 7 to 35 (i.e. four items contribute to both factors). The DSQ-12 composite scores can range from 12-60. Table 3.

Psychoform composite scores were significantly higher at age-groups 13-15 and 16-20 compared with age-group $10-12$ for girls $(\mathrm{p}<.001$ and $\mathrm{p}<.001)$, boys $(\mathrm{p}=.03$ and $\mathrm{p}<.001)$ as well as for girls and boys $(\mathrm{p}<.001$ and $\mathrm{p}<.001)$. Psychoform composite scores were also significantly higher for girls compared with boys at ages 10-12 ( $p=.04), 13-15(p<.001), 16-20(p<.001)$ and $10-20(\mathrm{p}<.001)$.

Somatoform composite scores were significantly higher at age-groups 13-15 and 16-20 compared with age-group 10-12 for girls ( $\mathrm{p}<.001$ and $\mathrm{p}<.001$ ), while boys at age 16-20 showed higher scores than boys at age 10-12 $(\mathrm{p}=.003)$. For girls and boys together, there were significantly higher scores at age-groups 13-15 and 16-20 compared with age-group 10-12 girls $(\mathrm{p}<.001$ and $\mathrm{p}<.001)$. Somatoform composite scores were also significantly higher for girls compared with boys at ages 13-15 (p<.001), 16-20 $(\mathrm{p}=.001)$ and 10-20 $(\mathrm{p}<.001)$.

The total DSQ-12 composite scores were significantly higher at age-groups 13-15 and 16-20 compared with age-group 10-12 for girls ( $p<.001$ and $p<.001)$, boys $(p=.04$ and $p<.001)$ as well as for girls and boys $(\mathrm{p}<.001$ and $\mathrm{p}<.001)$. The DSQ-12 composite scores were also 
significantly higher for girls compared with boys at all ages 10-12 $(p=.04), 13-15(p<.001), 16-$ $20(\mathrm{p}=.01)$ and $10-20(\mathrm{p}<.001)$.

\section{Insert table 3 here}

Reference values for subgroups (according to $84^{\text {th }}$ percentile/T-score 60 ), divided by gender and age-group are shown in Table 4.

\section{Insert table 4 here}

\section{Performance}

Using a normal $(n=122)$ and a clinical group $(n=25)$ and testing the performance of the DSQ12, using different cut-off values for when to classify individuals as belonging clinical or not, resulted in $\mathrm{AUC}=.819$ (95\% CI: .74-.90). For example, a cut-off value of the DSQ-12-score of 25 classified 4 out of 5 in the clinical group correct (sensitivity $=80 \%$ ) while only missclassifying less than three out of ten in the normal group (specificity $=73 \%$ ). Table 5 .

\section{Insert table 5 here}

\section{Discussion}

Dissociation is a mental health disorder that probably stems from traumatic events, much like posttraumatic stress disorder. The somatoform type of dissociation has not been fully acknowledged as a diagnosis under dissociation in DSM-5, but the symptoms are listed in the criteria for conversion disorder (Nijenhuis and Van der Hart, 2009). Much research shows that dissociation is both psychoform and somatoform (Gerge, 2013).

The aim of this study was to develop a new short self-rating questionnaire for dissociation, comprehending both psychoform and somatoform aspects, by using the Dis-Q and the SDQ- 
20 as a starting point. A second aim was to test the psychometrics and a third aim was to collect data concerning dissociation among a normative group of children and adolescents within age 10-20 years.

In the process of creating a new screening questionnaire for dissociation, it was important to get advice from collaborating clinicians who have experience working with the age group we have chosen to study. It was essential to take advice from clinicians into account in choosing the most suitable questions from the SDQ-20 and the Dis-Q. The advices from clinicians were needed partly because of the similarity in some of the top items from the 20 items questionnaire and partly because of the insecurity in which of the questions were most relevant. The psychoform part of the questionnaire chosen from the Dis-Q was easier to select as the variation of different kinds of questions made the top eight moderately distinct from each other.

The results from this study can be summarized in five main findings. First, our experience is that the DSQ-12 is easy to administer in schools and this makes it especially useful for initial screening.

Second, the psychometric properties of the DSQ-12 seem to be satisfactory. Concerning internal consistency, Cronbach's alpha for the DSQ-12 was high in both the pilot study and the main study. The convergent validity was satisfactory, as indicated by correlation between the dissociation subscale of the TSCC and the psychoform as well as the somatoform factor, in both the pilot and in the main study. In a previous study (Nilsson et al. (2008) the correlation between the TSCC dissociation subscale and the total Dis-Q-Sweden scale was $r=.75$, which is about the same as in this study.

Third, the construct validity was tested with EFA resulting in a two-factor solution where all psychoform items (items 1-8, originating from DIS-Q) loaded on factor 1, the psychoform 
factor, and where all somatoform items (items 9-12, originating from SDQ-20) loaded on factor 2, the somatoform factor. This is in line with the presumption that dissociation consists of psychoform as well as somatoform aspects. The psychoform and the somatoform aspects of dissociation were however not shown to be completely different phenomena, as indicated by the strong inter-factor correlations (.88 in EFA and .94 in CFA1). This supports the main idea of the merging psychoform items (from the DIS-Q) and somatoform items (from the SDQ-20) to comprehend the wider aspects of dissociation. Psychoform and somatoform aspects are sometimes also overlapping (Jepsen et al., 2014; Pullin et al., 2014; Soukup, et al., 2010) which was supported by the result that some variables loaded significantly on both factors on the EFA (in contrast with the model tested in CFA2 where they are forced to load on different factors). Concerning the items 1 and 2 that comes from the DIS-Q but relates to physical aspects in terms of feelings or actions related to the body therefore, it makes sense that these items also load on the somatoform factor. Item 11 that comes from the SDQ-20 is actually very similar to item 1 , but deals with feelings/thoughts about the body, and not directedly physical sensations, therefore, it makes sense that it also loads on the psychoform factor. The item number 4 "feel confused" loaded on both factors which was unexpected, and the explanation could be that confusion concerns both mind and body.

Fourth the DSQ-12 was tested among 451 subjects aged 10 through 20 . While there were no significant differences between girls and boys at 10-12 years of age, girls showed significantly higher dissociation scores than boys at 13-15 and at 16-20 years of age, for the psychoform as well as for the somatoform factors. Girls at age-groups 13-15 and 16-20 showed significantly higher scores on both factors compared to age-group 10-12. Boys showed the same pattern for the psychoform factor but for the somatoform factor only agegroup 16-20 showed significantly higher scores than age-group 10-12. This support earlier findings about gender differences, which also was a hypothesis in this study (Nilsson \& 
Svedin, 2006a). Over ages, age-groups 13-15 and 16-20 showed significantly higher scores for both dissociation factors compared with age-group 10-12 for girls. Boys showed similar pattern for the psychoform factor, but for the somatoform factor only age-group 16-20 showed significantly higher scores than age-group 10-12. Besides that, girls in general show higher levels of dissociation, this could reflect that girls physically mature earlier than boys and are therefore showing increased levels of somatoform dissociation earlier than boys. Finally, the DSQ-12 performed well when used to classify individuals as clinical or nonclinical.

Studies about dissociation patterns at childhood and adolescence are few and for the future this need to be further investigated in non-clinical as well as clinical populations. A short questionnaire as the DSQ-12 could be well suited for this purpose.

The somatoform and psychoform parts of dissociation have previously been viewed as two different parts of one disease but here in the DSQ-12 they are joined together as part of the same disease. Several of the studies referred to above have found both correlations and associations between the two conditions psychoform and somatoform dissociation, as seen, for example in Sar (2014). The questions in this new and much shorter version Dissociation Screening Questionnaire-12 (DSQ-12) are not completely new questions but have been created by using parts of longer questionnaires used in assessment for dissociation, the Dis-Q and the SDQ-20 that have previously been used in a variety of countries in different languages. The advantages with this new shorter version, the DSQ-12, is that the questions may be answered much more quickly, which must be considered as a benefit especially when it comes to children and adolescents who may not be ready to handle long questionnaires well.

Another benefit is that this new scale takes into consideration that dissociation can manifest itself both in psychoform and somatoform symptoms. This is the first time this approach has been used in studying a population of children and adolescents. 
Some limitations and weaknesses could be identified in this first study of the DSQ-12. First, the sample is not a representative national sample, which ought to be the goal in a future study to establish stable and normative data.

\section{Conclusion}

In conclusion, the newly developed Dissociation Screening Questionnaire 12 (DSQ-12) is valid and reliable as well as simple and short. It identifies both psychoform and somatoform dissociation using one formula. It is easy to use clinically or for instance in a nurse's office in school or at health care centers when there is concern with the possibility that an individual suffers from dissociation

Acknowledgements We thank the children, adolescents, who participated in this study Declaration of conflicting interests the author(s) declared no potential conflicts of interest with respect to the research, authorship, and/or publication of this article.

\section{References}

American Psychiatric Association. (2013). Diagnostic and Statistical Manual of Mental Disorders, fifth edition. Arlington, VA, American Psychiatric Association.

Beato, L., Rodriguez Cano, T., \& Belmonte, A. (2003 ). Relationship of dissociative experiences to body shape concerns in eating disorders. Eur Eat Disord Rev, 11,38-45.

Bob, P., Selesova P., Raboch, J., \& Kukla, L. (2013). 'Pseudoneurological' symptoms, dissociation and stress-related psychopathology in healthy young adults. BMC Psychiatry 2013(13), 149 Http:/www.biomedcental.com/1471-244X/13/149

Briere, J. (1996). Trauma symptom checklist for children (TSCC) professional manual. Odessa, FL: Psychological Assessment resources. 
Brown, T. A. (2006). Confirmatory factor analysis for applied research. New York, NY: The Guildford Press.

Bryman, A. (2001). Samhällsvetenskapliga metoder. Malmö: Liber.

CODEX Rules and guidelines. (2014). Research involving children. Accessed $-11^{\text {th }}$ March from http://codex.vr.se/manniska1.shtml (2014)"CODEX Rules and guidelines for research developed by the Swedish Research Council and Uppsala University. Accessed $-11^{\text {th }}$ March from, http://codex.vr.se/manniska1.shtml

Comasco, E., Gustafsson, P. A. ,Sydsjö, G., Agnafors, S., Aho, N., \& Svedin, CG. (2015).

Psychiatric symptoms in adolescents: FKBP5 genotype - early life adversity interaction effects. Eur Child Adolesc Psychiatry 24,1473-1483 DOI 10.1007/s00787-015-0768-3

Farina, B., Mazzotti, E., Pasquini, P., Nijenhuis, E., \& Di Giannantonio, M. (2011). Somatoform and psychoform dissociation among students. J Clin Psychology, 67(7), 665-672. Gerge, A. (2013).Vad har du varit med om som mår så här.PTSD och Dissociation hos Barn och unga. Förekomst,diagnostik och behandling. (What have you been though that feel like this. PSTD and dissociation among children and adolescents. Prevalence, diagnostics and treatment). Insidan förlag Stockholm.

Gerke, C., Mazzeo, S.,\& Kliewer, W. (2006). The role of depression and dissociation in the relationship between childhood trauma and bulimic symptoms among ethnically diverse female undergraduates. Child Abuse Neglect, 30,1161-72.

Hu, L., \& Bentler, P. M. (1999). Cutoff criteria for fit indexes in covariance structure analysis: Conventional criteria versus new alternatives. Structural Equation Modeling: A Multidisciplinary Journal, 6, 1-55.

Jepsen, E.K.K, Langeland, W., \& Heir, T. (2014). Early traumatized inpatients High psychoform and somatoform dissociation: Characteristics and treatment response. J Trauma and Dissociation 15, 572-587.doi.org/10.1080/15299732.2014.924461 
Kozlowska, K., Nunn, K.P., Rose, D., Morris, A., Ouvrier, R.A., \& Varghese, J. (2007).

Conversion disorder in Australian pediatric practice. J Am Acad Child and Adolescent Psychiatry 46, 68-75. DOI:10.1097/01.chi.0000242235.831.1f

Kukla, L., Selesova, P., Okrajek, P., \& Tulak, J. (2010). Somatoform dissociation and symptoms of traumatic stress in adolescents. Activitas Nervosa Superior, 52, 29-31.

Lanktree, C. B., Gilbert, A. M., Briere, J., Taylor, N., Chen, K., Maida, C. A., \& Saltzman, W. R. (2008). Multi-informant assessment of maltreated children: Convergent and discriminant validity of the TSCC and TSCYC. Child Abuse \& Neglect: The International Journal, 32, 621-625.

Maaranen, P., Tanskanen, A., Haatainen, K., Koivurmaa-Honkanen, H., Hintikka, J., \& Viianamäki, H. (2004). Somatoform dissociation and adverse childhood experiences in the general population. J Nerv Mental Dis, 192, 337-42.

McShane, J., \& Zirkel, S. (2008). Dissociation in the binge-purge cycle of bulimia nervosa. $J$ Trauma Dissociation, 9, 463-79.

Mueller-Pfeiffer, C., Schumacher, S., Martin-Soelch, C., Pazhenkottil, A.P., Wirtz, G., Fuhrhans, C., Hindermann, E., Assaloni, H., Briner, D. P., \& Rufer, M. (2010). The validity and reliability of the German version of the somatoform dissociation questionnaire (SDQ-20). J Trauma and Dissociation 11(3), 337-357, DOI: 10.1080/15299731003793450.

Nijenhuis, E. (2004). Somatoform dissociation: Phenomena, measurement, and theoretical issues. New York: Norton.

Nijenhuis, E., Spinhoven, P., van Dyck, R., van der Hart, O., \& Vanderlinden, J. (1996). The development and psychometric properties of the somatoform dissociation questionnaire (SDQ20). J Nerv Mental Dis 184, 688-94.

Nijenhuis, E., \& Van der Hart, O. (2009). Dissociative Disorders. (2th ed.) Oxford: Oxford University Press. 
Nijenhuis, E., Van der Hart, O., \& Steele, K. (2006). The Haunted Self. London \& New York: W.W. Norton \& Company.

Nijenhuis ERS. Somatoform dissociation and somatoform dissociative disorders. In: Dell PF, O'Neil JA, editors. Dissociation and the dissociative disorders: DSM-V and beyond. New York: Routledge, 2009, p. 259-285

Nilsson, D., \& Svedin, CG. (2006a). Evaluation of the Swedish version of Dissociation questionnaire (DIS-Q), Dis-Q-Sweden, among adolescents. J Trauma and Dissociation 7, 6589.

Nilsson D, Svedin CG (2006b). Dissociation among Swedish adolescents and the connection to trauma. An evaluation of the Swedish version of the Adolescent dissociative experience scale. J Nerv Mental Dis 194, 684-689.

Nilsson, D., Wadsby, M., \& Svedin, CG. (2008). The psychometric properties of the Trauma Symptom Checklist for Children (TSCC) in a sample of Swedish children. Child Abuse \& neglect, 32, 627-636.

Nilsson, D., Gustafsson, PE.,\& Svedin, CG. (2010). Self-reported potentially traumatic life events and symptoms of post-traumatic stress and dissociation. Nord J Psychiatry 64, 19-26.

Nilsson, D., \& Svedin, CG. (2010). Manual Supplement till, John Briere, Trauma Symptom Checklist for Children. Stockholm: Hogrefe Psykologiförlaget.

Nilsson, D., Holmqvist, R., \& Jonsson, M. (2011). Self-reported attachment style, trauma exposure and dissociative symptoms among adolescents. Attachment \& Human development, 13(6), 579-595.

Nilsson, D., Lejonclou, A., Svedin, CG., Jonsson, M., \& Holmqvist, R. (2014). Somatoform dissociation among Swedish adolescents and young adults: The psychometric properties of the Swedish versions of the SDQ-20 and SDQ-5. Nord j Psychiatry 69(2), 152-160. 
Pullin, M.A., Webster, R.A., \& Hanstock, T.L. (2014). Psychoform and Somatoform Dissociation in a Clinical Sample of Australian Adolescents. J Trauma and Dissociation, 15(1), 66-78, DOI: 10.1080/15299732.2013.828149

Putnam, F.W. (1997). Dissociation in children and adolescents. London: The Guilford Press. R Core Team (2018). R: A language and environment for statistical computing. R Foundation for Statistical Computing, Vienna, Austria. URL https://www.R-project.org/ RStudio Team (2016). RStudio: Integrated Development for R. RStudio, Inc., Boston, MA URL http://www.rstudio.com/.

Sar, V., \& Ross, C. (2006) Dissociative Disorders as a Confounding Factor in Psychiatric Research. Psychiatric Clin North Am. 29(1), 129-144

Sar,V., Islam, S., \& Öztürk, E. (2009) Childhood emotional abuse and dissociation in patients with conversion symptoms. Psychiatry and Clinical Neurosciences 63, 670677.doi:10.1111/j.1440-1819.2009.02012.x

Sar, V. (2014) The many faces of dissociation: Opportunities for innovative research in psychiatry. Clinical Psychopharmacology and Neuroscience, 12(3), 171-179.

Silberg, J., \& Waters, F. (1996) The dissociative child, diagnosis, treatment and management. Lutherville Maryland: The Sidran Press.

Soukup, J., Papezova, H., Kubena, A. A., \& Mikolajova, V. (2010). Dissociation in non-clinical and clinical sample of Czech adolescents: Reliability and validity of the Czech version of the Adolescent Dissociative Experience Scale. Eur Psychiarty, 25, 390-395.

Steinberg, M. (1994) .Structured clinical interview for DSM-IV dissociative disorder (SCIDD), revised. Washington, DC: American Psychiatric Press.

Svedin, C.G., Nilsson, D., \& Lindell, C. (2004). Traumatic experiences and dissociative symptoms among Swedish adolescents. A pilot study using Dis-Q-Sweden. Nordic J psychiatry, 58, 349-355. 
Vanderlinden, J., van Dyck, R., Vandereycken, W., Vertnommen, H., \& Verkes, R.J., (1993). The dissociation Questionnaire (Dis-Q): Devlopment and characteristics of a new self -report questionnaire. Clin Psychology \& Psychotherapy ,1(1), 21-27.

Vanderlinden, J., \& Vandereycken, W. (1997) Trauma, dissociation, and impulse dyscontrol in eating disorders. Bristol: Brunner/Mazel, Publishers.

World Health Organization (1992). International Classification of Diseases, $10^{\text {th }} \mathrm{ed}$. (ICD10). Geneva: World Health Organization.

World Health Organization. (2018). International Classification of Diseases, $11^{\text {th }} \mathrm{ed}$. (ICD11). Geneva: World Health Organization.

Yu, C. Y. (2002). Evaluating cutoff criteria of model fit indices for latent variable models with binary and continuous outcomes. Unpublished doctoral dissertation. Los Angeles: University of California. 
Table 1

The complete 12 item Dissociation Screening Questionnaire (DSQ) and the item-total correlations for each item with DIS-Q and SDQ-20 respectively.

\begin{tabular}{lc}
\hline Items & \\
\hline From DIS-Q & $\begin{array}{c}\text { Item-total } \\
\text { correlation }\end{array}$ \\
Item number & .65 \\
New (OId) & .68 \\
\hline 1. (3) Sometimes it seems as if I have lost contact with my body & .65 \\
2. (11) At times I feel a great distance between myself and the things I think and do \\
3. (12) At times I wonder who I am exactly \\
4. (17) It happens that I feel confused \\
5. (20) In particular situations, I experience myself as a split personality \\
6. (28) It happens that I get the feeling that my body is undergoing an alteration \\
7. (41) Sometimes I think or do something against my liking in a way that does not \\
suit me at all & .65 \\
8. (57) It happens that I have the feeling that my mind is split up & .65 \\
\hline From SDQ-20 & .62 \\
\hline 9. (7) I grow stiff for a while & .56 \\
10. (15) I am paralyzed for a while & .56 \\
11. (19) It is as if my body, or part of it, has disappeared \\
12. (20) I have an attack that resembles an epileptic seizure \\
\hline
\end{tabular}


Table 2

Factor analysis for the questions on DIQ-12. Exploratory factor analysis (EFA) is based on the training-set $(n=225)$ and Confirmatory Factor Analyses (CFA) are based on the test-set $(n=225)$.

\begin{tabular}{|c|c|c|c|c|c|c|}
\hline \multirow[b]{2}{*}{ Item } & \multicolumn{2}{|c|}{ EFA } & \multicolumn{2}{|c|}{ CFA1 } & \multicolumn{2}{|c|}{ CFA2 } \\
\hline & F1 & F2 & F1 & F2 & F1 & F2 \\
\hline $\begin{array}{l}\text { 1. Sometimes it seems as if I had lost } \\
\text { contact with my body }\end{array}$ & $.42^{*}$ & $.50^{*}$ & $0.59 *$ & $0.45^{*}$ & 1.00 & - \\
\hline $\begin{array}{l}\text { 2. At times I feel a great distance } \\
\text { between myself and the things I think } \\
\text { of and do }\end{array}$ & $.63^{*}$ & $.23 *$ & $0.66^{*}$ & $0.35^{*}$ & $0.96^{*}$ & - \\
\hline 3. At times I wonder who I am exactly & $.74^{*}$ & .10 & $0.98 *$ & - & $0.91 *$ & - \\
\hline 4. It happens that I feel confused & $.46^{*}$ & $.40^{*}$ & $0.93^{*}$ & 0.09 & $0.95^{*}$ & - \\
\hline $\begin{array}{l}\text { 5. In particular situations I experience } \\
\text { myself as a split personality }\end{array}$ & $.99 *$ & -.18 & $0.92 *$ & - & $0.86^{*}$ & - \\
\hline $\begin{array}{l}\text { 6. It happens that I get the feeling that } \\
\text { my body is undergoing an alteration }\end{array}$ & $.47^{*}$ & .19 & $0.88^{*}$ & - & $0.81 *$ & - \\
\hline $\begin{array}{l}\text { 7. Sometimes I think or do something } \\
\text { against my liking in a way that does } \\
\text { not suit me at all }\end{array}$ & $.73^{*}$ & .07 & $0.90 *$ & - & $0.83^{*}$ & - \\
\hline $\begin{array}{l}\text { 8. It happens that I have the feeling that } \\
\text { my mind is split up }\end{array}$ & $.84^{*}$ & -.00 & 1.00 & - & $0.93 *$ & - \\
\hline 9. I grow stiff for a while & .16 & $.74 *$ & - & $0.91 *$ & - & $0.91 *$ \\
\hline 10. I am paralyzed for a while & .01 & $.94^{*}$ & - & 1.00 & - & 1.00 \\
\hline $\begin{array}{l}\text { 11. It is as if my body, or part of it, has } \\
\text { disappeared }\end{array}$ & $.34^{*}$ & $.58^{*}$ & $0.37^{*}$ & $0.65^{*}$ & - & $0.98^{*}$ \\
\hline $\begin{array}{l}\text { 12. I have an attack that resembles an } \\
\text { epileptic seizure }\end{array}$ & -.21 & $.90^{*}$ & - & $0.58^{*}$ & - & $0.58 *$ \\
\hline
\end{tabular}

Model fit

\begin{tabular}{llll}
\hline$\chi^{2}$ & 103.29 & 142.78 & 156.88 \\
$d f$ & 43 & 49 & 53 \\
$p$ & $<.001$ & $<.001$ & $<.001$
\end{tabular}


RMSEA [90\% CI]

.079 [.060 - .099]

$.092[.075-.110]$

$.093[.077-.110]$

CFI

.983

.985

.984

TLI

.974

.980

.980

$S R M R$

.050

WRMR

.835

.909

\begin{tabular}{lllllll}
\hline Correlation between factors F1 and F2 & .88 & & .94 & \multicolumn{3}{c}{.98} \\
\hline Correlations with TSCC dissociation subscale & $.69 \dagger$ & $.61 \dagger$ & $.76{ }^{+\dagger}$ & $.70^{\dagger \dagger}$ & $.75^{+\dagger}$ & $.74{ }^{\dagger \dagger}$ \\
\hline Cronbach's $\alpha$ & .89 & .85 & .93 & .90 & .92 & .86
\end{tabular}

Note: * indicates significant loadings at 5\% level. EFA $=$ Exploratory Factor Analysis, coefficients are geomin rotated factor loadings. CFA1 = Confirmatory Factor Analysis of the EFA-model and CFA2 = Confirmatory Factor Analysis on the theoretically defined model, where coefficients are parameter estimates. Correlations are shown as Spearman's rho. ${ }^{\dagger} n=98,{ }^{\dagger \dagger} n=100$. 
Table 3

Median and inter-quartile range of composite scores for each factor and for all DSQ-12 items over gender and age-groups.

\begin{tabular}{|c|c|c|c|c|c|c|c|c|c|c|c|c|}
\hline \multirow[b]{2}{*}{ Age } & \multicolumn{4}{|c|}{ Girls } & \multicolumn{4}{|c|}{ Boys } & \multicolumn{4}{|c|}{ All } \\
\hline & Factor 1 & Factor 2 & DSQ-12 & $\mathrm{n}$ & Factor 1 & Factor 2 & DSQ-12 & $\mathrm{n}$ & Factor 1 & Factor 2 & DSQ-12 & $\mathrm{n}$ \\
\hline $10-12$ & $11(9-15)$ & $8(7-9)$ & 15 (12-19) & 69 & $10(9-13)$ & $7(7-8)$ & $13(12-16)$ & 51 & $11(9-14)$ & $8(7-9)$ & $14(12-17)$ & 121 \\
\hline $13-15$ & $17(11-23)$ & $10(8-15)$ & 21 (14-29) & 78 & 11 (10-15) & $8(7-9)$ & 15 (13-19) & 42 & $14(10-20)$ & $9(7-13)$ & $18(14-24)$ & 120 \\
\hline $16-20$ & $16(12-22)$ & $9(8-13)$ & $20(15-26)$ & 123 & $13(11-18)$ & $8(7-11)$ & $16(14-22)$ & 86 & $15(11-20)$ & $9(8-12)$ & $19(14-23)$ & 212 \\
\hline All & $15(11-20)$ & $9(8-12)$ & $18(14-25)$ & 270 & $12(10-16)$ & $8(7-9)$ & $15(13-20)$ & 178 & $13(10-18)$ & 8 (7-11) & $17(13-22)$ & 451 \\
\hline
\end{tabular}

Note: possible range for factor 1 is $9-45$, possible range for factor 2 is 7-35, possible range for SDQ12 is 12-60. 
Table 4

$84^{\text {th }}$ percentiles in the different subgroups (corresponding to T-scores of 60 in normally distributed samples) for the composite-scores of factor 1 and factor 2 respectively.

\begin{tabular}{lccccccccccc}
\hline & & Girls & & & \multicolumn{3}{c}{ Boys } & & \multicolumn{3}{c}{ All } \\
Age & Factor 1 & Factor 2 & $\mathrm{n}$ & & Factor 1 & Factor 2 & $\mathrm{n}$ & & Factor 1 & Factor 2 & $\mathrm{n}$ \\
\hline $10-12$ & 17 & 10 & 69 & & 15 & 9 & 51 & & 16 & 10 & 121 \\
$13-15$ & 30 & 20 & 78 & & 18 & 10 & 42 & & 26 & 15 & 120 \\
$16-20$ & 25 & 16 & 123 & & 20 & 12 & 86 & & 23 & 14 & 212 \\
All & 24 & 15 & 270 & & 19 & 11 & 178 & 21 & 13 & 451 \\
\hline
\end{tabular}

Note: possible range for factor 1 is $9-45$ and possible range for factor 2 is 7-35. 
Table 5. DSQ-12 scores (composite-scores, i.e. sum of scores of each used for classification of Normal $(n=122)$ and Clinical $(n=25)$ groups. The classifications show how normal and clinical individuals are classified into Normal or Clinical groups with corresponding cutoff. The cutoffs are inclusive which means that if a person is classified to the clinical group if the DSQ-12 score is the same as the cutoff or above. Performance shows the corresponding sensitivity and specificity for each cutoff. The AUC was .819 (95\% Cl: .74-.90).

\begin{tabular}{|c|c|c|c|c|c|c|}
\hline \multirow[b]{3}{*}{ Cutoffs } & \multicolumn{4}{|c|}{ Classifications } & & \\
\hline & \multicolumn{2}{|c|}{ Normal $(n=122)$} & \multicolumn{2}{|c|}{ Clinical $(n=25)$} & \multicolumn{2}{|c|}{ Performance } \\
\hline & $\begin{array}{c}\text { Classified as } \\
\text { normal group }\end{array}$ & $\begin{array}{l}\text { Classified as } \\
\text { clinical group }\end{array}$ & $\begin{array}{l}\text { Classified as } \\
\text { normal group }\end{array}$ & $\begin{array}{l}\text { Classified as } \\
\text { clinical group }\end{array}$ & Sensitivity & Specificity \\
\hline 15 & 34 & 88 & 1 & 24 & 0.96 & 0.28 \\
\hline 20 & 68 & 54 & 2 & 23 & 0.92 & 0.56 \\
\hline 25 & 89 & 33 & 5 & 20 & 0.80 & 0.73 \\
\hline 30 & 104 & 18 & 11 & 14 & 0.56 & 0.85 \\
\hline 35 & 114 & 8 & 17 & 8 & 0.32 & 0.93 \\
\hline 40 & 119 & 3 & 23 & 2 & 0.08 & 0.98 \\
\hline 45 & 121 & 1 & 25 & 0 & 0 & 0.99 \\
\hline
\end{tabular}




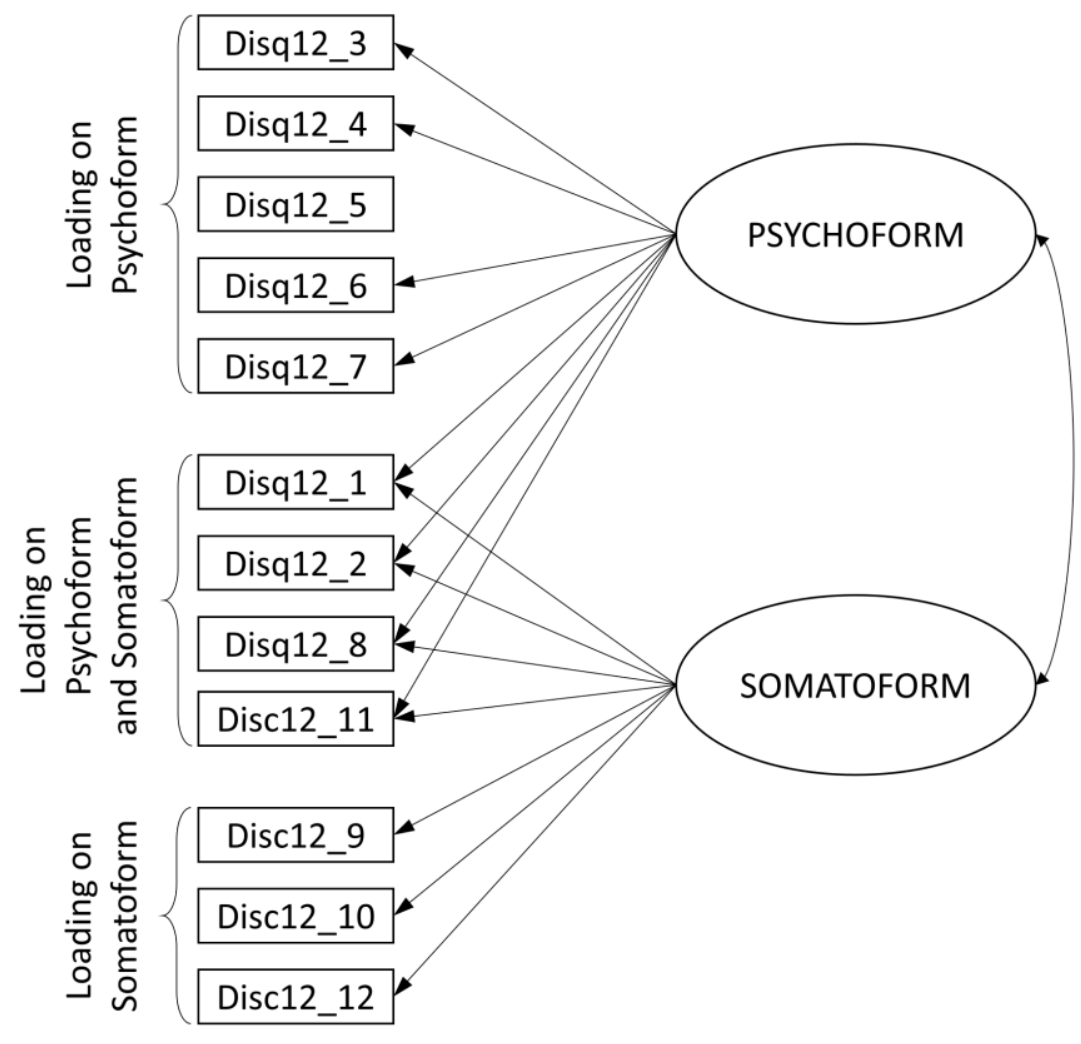

(a)

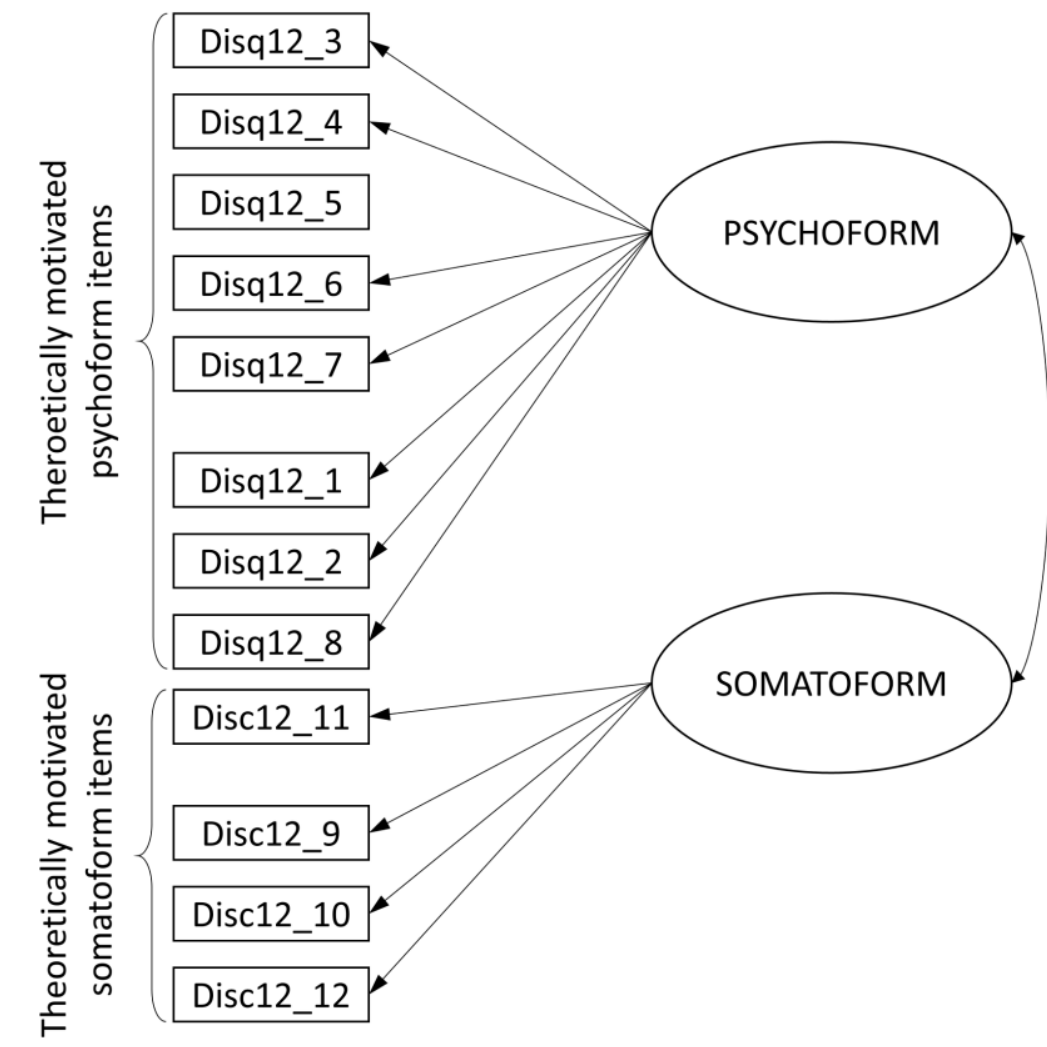

(b)

Figure 1 Schematic view of (a) the two-factor model generated by the Exploratory Factor Analysis (EFA) and tested for by the first Confirmatory Factor Analysis (CFA1) and (b) the theoretically defined model tested for by the second Confirmatory Factor Analysis (CFA2). Disq12_nr shows, where $n r=1,2,3, \ldots, 12$ represent the 12 different questions, where questions 1-8 origins from the DIS-Q and questions $9-12$ origins from the SDQ-20 


\section{Instruction and Explanation for the Questionnaire 12}

Fill in the white boxes of the questionnaire. Above, you fill in the name or Client-ID, Age, Gender and Date.

This is a list of 12 different problems that people may experience sometimes. Read through each problem and make an $X$ in the box with the answer that best suits you.

1 Sometimes it seems as if I have lost contact with my body

At times I feet
think and do

3 At times I wonder who I am exactly

4 It happens that I feel confused

5 In particular situations, I experience myself as a split personality

6 It happens that I get the feeling that my body is undergoing an alteration

7 Sometimes I think or do something against my liking in a way that does not suit me at all

8 It happens that I have the feeling that my mind is split up

$9 \quad$ I grow stiff for a while

10 I am paralyzed for a while

11 It is as if my body, or part of it, has disappeared

12 I have an attack that resembles an epileptic seizure

\begin{tabular}{|c|c|c|c|c|}
\hline Never & Seldom & $\begin{array}{l}\text { Some- } \\
\text { times }\end{array}$ & Often & Always \\
\hline 1 & 2 & 3 & 4 & 5 \\
\hline 1 & 2 & 3 & 4 & 5 \\
\hline 1 & 2 & 3 & 4 & 5 \\
\hline 1 & 2 & 3 & 4 & 5 \\
\hline 1 & 2 & 3 & 4 & 5 \\
\hline 1 & 2 & 3 & 4 & 5 \\
\hline 1 & 2 & 3 & 4 & 5 \\
\hline 1 & 2 & 3 & 4 & 5 \\
\hline 1 & 2 & 3 & 4 & 5 \\
\hline 1 & 2 & 3 & 4 & 5 \\
\hline 1 & 2 & 3 & 4 & 5 \\
\hline 1 & 2 & 3 & 4 & 5 \\
\hline
\end{tabular}

